\title{
CORRELATION BETWEEN DEGREE OF PULP INFLAMMATION AND SUCCESS RATE OF MTA PULPOTOMY IN PRIMARY TEETH: PROSPECTIVE COHORT STUDY
}

\author{
Nihal kabel", Shaimaa O. Zayed ${ }^{* *}$, Hoda K. Shamloula** and Ghada M. Mahmoud ${ }^{* * * *}$
}

\begin{abstract}
Objective: Many studies reported that the subjective clinical and radiographic examination lack the accuracy about the biological status of the pulp tissue. cytokines produced by dental pulp cells may reflect the degree of pulpal inflammation. The purpose of this study is to Correlate the cytokine levels of (IL-1 $\alpha$, IL-6, and IL-8) present in coronal dental pulp of primary molars with the success rate of MTA based vital pulpotomy over 18 months follow up period.
\end{abstract}

Methods: 40 primary molars were enrolled. The cases are divided into group A (caries level code 5), group B (caries level code 6). Blood and pulp tissue were collected from the pulp cavity by sterile cotton pellet. The pellet was placed in $0.5 \mathrm{ml}(500 \mu \mathrm{l})$ phosphate buffered saline solution (PBS) to 1/10 final volume in a heparin-coated tube. Levels of cytokines IL-1 $\alpha$, IL-6 and IL-8 were measured by using ELISA.

Results: We found that IL-1 $\alpha$, IL-6 and IL-8 were significant higher in group (B) than in (A). IL-6 showed the most significant value of expression in comparison to IL-1 $\alpha$ and IL-8 (p-value: $0.011,0.014 \& 0.027$ respectively) which denote the prominent role of IL- 6 during the inflammatory process in the pulp tissue of primary molars.

Conclusion: IL-1 $\alpha$, IL-6 and IL-8 cytokine expression in primary pulp molars increase with caries progression. Although the significant difference in the cytokine level expression between group A and B, a high success rate of MTA vital pulpotomy was found during the follow up period in both groups.

KEY WORDS: Cytokines, vital pulp therapy, caries level, pulp inflammation. ELISA

\footnotetext{
* Associate Professor Associate Professor at Pediatric Dentistry Department. Faculty of Dentistry. Misr University for Science \& Technology.

** Associate Professor at Oral \& Maxillofacial Pathology Department. Faculty of Dentistry. Cairo University.

*** Lecturer and Head of Biochemistry Department at College of Pharmacy and drug manufactory. Misr University for Science \& Technology. Ph.D. molecular biology at CUNY, USA.

**** Associate Professor at Pediatric Dentistry Department. Faculty of Dentistry. Modern Sciences and Arts University
} 


\section{INTRODUCTION}

Vital pulp therapy pulpotomy in primary teeth has long been a subject of debate owing to the unpredictability of its long term result in many cases ${ }^{[1]}$. Till now, the factors affecting the success of vital pulp therapy are still under investigations by the researchers. Correct evaluation of the degree of pulpal inflammation is a main factor for successful vital pulp therapy ${ }^{[2]}$. Histopathological examination might be an accurate tool for diagnosis of the biological condition of the pulp, , however, this might necessitates complete pulpal excision which cannot be done in the clinical condition ${ }^{[3]}$.

The doctors depend on the clinical signs, sensitivity tests, and radiographic examination as well as, color, bleeding time, and volume of blood to judge the pulp biological condition ${ }^{[4-6]}$. However, these parameters are subjective (except for measuring time for hemostasis), and they might not reflecting the actual histopathological condition of the pulp ${ }^{[7]}$.

There has been an argument regarding the bleeding site to be evaluated; a group of researchers believe that the one at the exposure site highly reflects the degree of pulpal inflammation, and that this is the only site that can images the biological status of the pulp. ${ }^{[2]}$. Others disagreed with this opinion, claiming that blood at amputation site is the one that counts $^{[7,8]}$. A third group of investigators believe that both sites should be taken into consideration ${ }^{[9-10]}$. In fact, this controversy in opinion along with diversity in the way of collecting data have given rise to hindering standardization, therefore, complicating the comparison between studies ${ }^{[11]}$.

The infected dentin surrounding the exposure site constitutes a source of bacterial contamination, and may therefore result in inflammatory response as well as necrosis ${ }^{[12]}$. Thus, pulpal inflammation may compromise the success of vital pulpotomy in carious exposed primary teeth , as it's considered rather challenging to objectively evaluate the extent of pulpal inflammation and accordingly decide the most appropriate pulp treatment procedure [13,14]. Since it is difficult to objectively measure the level of inflammation and suitability of vital pulp treatment ${ }^{[15]}$. So a growing interest on pulpal blood analysis to detect the severity of pulpal tissue inflammation ${ }^{[2,3,14]}$.

The severity of pulpal inflammation is most of the time closely related to the size and type of exposure, whether it's mechanical or carious ${ }^{[3]}$. Some authors consider mechanical and carious pulp exposure as separate entities, owing to their distinctive pathological effects on pulpal tissue ${ }^{[11,12]}$. When it comes to an objective evaluation of the degree of pulpal inflammation, It's the cytokines levels at the exposure site that can give an accurate information regardless of the type of exposure ${ }^{[4]}$.

A more objective method is necessary for research purposes; one that gives an accurate and clear idea about pulpal inflammation. This can be obtained from the level of inflammatory mediators in the pulpal blood ${ }^{[16]}$. Cytokines are are small polypeptides secreted by mononuclear phagocytes, fibroblasts, leucocytes and other inflammatory cells ${ }^{[17]}$.

Pro-inflammatory cytokines are involved in the regulation and development of inflammation, while anti-inflammatory cytokines are involved in supression of inflammation ${ }^{[17]}$. the pro-inflammatory cytokines IL $1 \alpha$ and $\beta$ are the earliest to be liberated in inflammation and are correlated with acute and chronic phases of this process. IL- $1 \alpha$ and $\beta$ promote IL-8 production in dental pulp cells where IL- $1 \alpha$ and $\beta$ have been reported to repress pulp cell proliferation and activate collagen degradation in dental pulp by remodeling of metalloproteinases ${ }^{[18]}$. IL-8 is effectual chemotactic cytokine that enroll the neutrophils in reaction to bacterial side products and toxins that is why high level of IL- 8 is observed in inflamed dental pulp which suggest that IL- $1 \alpha$ and $\beta$ as well as IL-8 are dominant in the pathogenic events of pulpal diseases ${ }^{[19]}$.

Interluekin-6 represent a major moderator of the 
host reaction following tissue injury and infection as well as inflammation. It is synthesized in reaction to inflammation and trauma by a diversity of cells such as macrophages, neutrophils, keratinocytes, fibroblasts, and endothelial cells ${ }^{[20]}$. It has been reported to activate a number of biologic events such as antibody-producing cells, activation of $\mathrm{T}$ cells, B cell differentiation, synthesis of acute-phase proteins B cells, hematopoiesis, stimulation of angiogenesis, vascular permeability, and osteoclast differentiation also, IL-6 is corresponded with recruitment of neutrophils and irreversible tissue damage ${ }^{[21,22]}$.

The level of IL-6 was revealed to be significantly higher in tooth with caries exposure and irreversible pulpitis in contrast to healthy tooth, which suggest that cytokine assessment in pulpal blood may aid in the diagnosis of pulpal inflammation ${ }^{[22]}$. Previous study observed excess levels of IL-6 in inflamed human dental pulp and periapical lesions in contrast with healthy pulp, suggesting that IL-6 is liberated in pathologic lesions ${ }^{[23]}$. Furthermore, IL-6 levels were found to be upraised in symptomatic human periapical lesions in contrast with asymptomatic lesions, suggesting that extra IL-6 liberation might be correlated with magnification of inflammation and aggravated clinical symptoms ${ }^{[24]}$.

Nowadays, it is possible to measure multiple inflammatory markers from small amounts of blood samples, such as those expressed at exposure site of the pulp tooth. ${ }^{[25]}$. In the present study, we measured the interleukin levels in blood samples of pulp tissue by using ELISA which is considered reliable, accurate and sensitive immunoassay for measuring antigen antibody reaction in medicine ${ }^{[26]}$.

Pulpotomy remains the most common and universally preferred pulp therapy for treatment of primary molars suffering carious cavitated lesions ${ }^{[27]}$. During the past several years, mineral trioxide aggregate (MTA) was used successfully in endodontic treatment of permanent teeth and good substitute of formocresol in primary teeth vital pulpotomy ${ }^{[28]}$.

MTA acts on the sealing ability and produces a suitable media for the healing mechanism. After hardening, MTA in contact with pulp can react with tissue fluids to produce calcium hydroxide forming calcite crystals that gather fibronectin, which is responsible for cell connection and differentiation maintaining pulp vitality and could stimulate repair.

Many studies revealed that MTA of high success rate as shown in the clinical and radiographic results but the degree of pulpal inflammation is of great importance in the outcome of such agent and hence for successful vital pulp therapy ${ }^{[29]}$.

The purpose of this study is to correlate the cytokine level of (IL-1 $\alpha$, IL-6, and IL-8) present in coronal dental pulp of primary molars with the success rate of MTA based vital pulpotomy over the follow up period of 18 months.

\section{MATERIALS AND METHODS}

Ethical approval. The protocol for this study was approved by the Ethical Committee for Clinical Research, faculty of dentistry, Cairo University. For all enrolled children, a written informed consent was obtained, in which the detailed treatment was explained to the parents or care giver

Total children examined during the study was 65 and the number of children that met the inclusion and exclusion criteria were 40 children, whose age ranged from 4-7 year old, selected from those attending the outpatient clinic of MUST university. All selected children were medically free and did not used any anti-inflammatory medication during the period of the study (between June 2019- December 2020).

Forty Primary molar teeth from forty children were included based on the following clinical and radiological inclusion criteria: group A: (a) no clinical symptoms (e.g., no pain on percussion, 
history of swelling, or sinus tract); (b) no spontaneous pain; (c) no radiographic signs of internal/external resorption, widened periodontal ligament space, or furcal/peri- apical radiolucency; (d) physiological root resorption of no more than one-third the root length; and (e) Caries level ICCMS ${ }^{T M}$ (Stage 5= radiolucency reaching the inner $1 / 3$ of dentin, $)^{[30]}$. (f) Hemostasis of pulpal tissue can be achieved within first 2-3 minutes during the clinical procedure ${ }^{[31]}$.

Group B inclusion criteria: (a) clinical symptoms of pulp inflammation (pain with stimulus, intermittent pain but no history of swelling), (b) no radiographic signs of internal/external resorption, no furcal/peri- apical radiolucency; (c) physiological root resorption of no more than one-third the root length (d) Caries level according ICCMS ${ }^{T M}$ Stage 6= radiolucency into the pulp, clinically cavitated ${ }^{[30]}$. (e) Hemostasis of pulpal tissue can be achieved within first 5 minutes during the clinical procedure ${ }^{[31]}$.

\section{Exclusion criteria for both groups:}

- History of swelling.

- Presence of radiographic signs of of internal/ external resorption.

- Presence of furcal/peri- apical radiolucency.

- Physiological root resorption more than onethird the root length.

- Hemostasis of pulpal tissue cannot be achieved within first 5 minutes during the clinical procedure.

- Teeth with necrotic pulp, purulent discharge from canal orifices.

\section{Sample size}

The calculation was done using the comparison of IL-8 level between 4-7 years old children with carious $2^{\text {nd }}$ primary molars. Upon searching the literature, we failed to retrieve relevant results that can be used to build a sample size. Therefore we decided to do pilot study. According to our pilot results, the mean \pm SD of IL-8 level in group B was approximately $2.13 \pm 0.99 \mathrm{pg} / \mathrm{ml}$, while in group A it was approximately $1.58 \pm 0.37 \mathrm{pg} / \mathrm{ml}$. Accordingly, we calculated that the minimum proper sample size was 14 molar teeth in each group to be able to reject the null hypothesis with $80 \%$ power at $\alpha$ $=0.05$ level using Student's $t$ test for independent samples. Sample size calculation was done using PS Power and Sample Size Calculations software, version 3.0.11 for MS Windows (William D. Dupont and Walton D., Vanderbilt University, Nashville, Tennessee, USA). The study was performed on 40 second primary molars to avoid regression analysis during the study. 4-7-year-old children will be selected from those attending the outpatient clinics of MUST and MSA outpatient pediatric dental clinics.

\section{Clinical procedure}

\section{Procedure of pulpotomy}

Each child received an injection with local anaesthesia with no vasoconstrictor (scandonest 3\% plain, Mepivacaine Hydrochloride 3\%, septodont), the teeth were then isolated using rubber dam, carious dentin was excavated using round bur mounted on low speed hand piece. Teeth which revealed pathologic pulp exposure were included in the study

\section{Samples collection}

The roof of the pulp chamber was removed exposing the pulp surface. Blood and pulp tissue were carefully collected from the pulp cavity by using a tiny sterile cotton pellet. The pellet was left for 30 to 60 seconds in the cavity to allow complete absorption of the pulpal blood. Each pellet allows absorption of about $50 \mu 1$ of blood. The pellet was placed in $0.5 \mathrm{ml}(500 \mu \mathrm{l})$ phosphate buffered saline solution (PBS) to $1 / 10$ final volume in a heparincoated tube. The tube was immediately immersed in ice box. All samples were treated the same way ${ }^{[32]}$.

All primary molars included in the study were treated with vital pulpotomy with a MTA (BIO 
MTA, PPH CERKAMED Wojciech Pawlowski, Wola, Poland, and Kwiatkowiego) and restored with stainless steel crowns. (3M ESPE Dental Products).

\section{Samples Preparation}

Samples were vortexed for 2 minutes and sterilized glass rods were used to push out blood and tissue from the cotton pellets in order to release cytokines in the solution. Samples were centrifuged at $10,000 \mathrm{rpm}$ for $15 \mathrm{~min}$. at $4^{\circ} \mathrm{C}$, and cell culture supernatants were collected in sterilized Eppendorf tubes. The tubes were labeled and stored at $-20{ }^{\circ} \mathrm{C}$ until they were tested all together for cytokines levels using ELISA ${ }^{[33,34]}$.

\section{ELISA procedure for estimation of cytokine levels}

Levels of cytokines IL- $1 \alpha$, IL- 6 and IL-8 were measured by using enzyme-linked immunosorbent assay (ELISA). BioVision's ELISA kits (Milpitas, California, USA) were used for the quantitative measurements of human cytokines in cell culture supernatants. The ELIZA procedure was done at Animal Reproduction research Institute (highly equipped governmental institute), Al Haram, Giza.

BioVision's ELISA kit is a sandwich ELISAassay for quantitative measurements of human cytokines in serum, plasma, cell culture supernatants and biological fluids. The density of the color obtained is proportional to human cytokine amount in the sample. These specific kits were used to determine IL-1 $\alpha$, IL- 6 and IL- 8 in all the collected samples with sensitivities of $<0.5,<0.3$ and $<18.75 \mathrm{pg} / \mathrm{ml}$ respectively. Cytokines concentration of IL- $1 \alpha$ and IL-6 were expressed as pictograms per milligrams total protein. While Cytokine IL-8 concentration was expressed as nanogram per milligram total protein. All samples were tested in duplicates.

\section{Data analysis and Cytokines concentration:}

ELISA assay were used to determine the concentration of interleukins (IL-1 $\alpha$, IL- 6 and IL8) of the patients' blood samples. Assay was diluted 5-folds with deionized water. Standard was prepared by adding $15 \mu 1$ of cytokine standard (20ng/ml) into $985 \mu \mathrm{l}$ assay diluent to prepare $300 \mathrm{pg} / \mathrm{ml}$ standard solution which was used to prepare dilution series.

Detection of the antibody concentration was prepared by adding $100 \mu \mathrm{l}$ of assay diluent to the detection antibody vials. The assay protocol was followed and cytokines concentrations were immediately detected by reading absorption at $450 \mathrm{~nm}$. The mean absorption for each set of duplicate standards, control and samples were calculated. The average zero standard optical density was subtracted. Sigma plot software was used to draw graphs with samples concentrations on the $\mathrm{X}$-axis and absorbance on the Y-axis. Data analysis was performed by using SPSS for Windows (version 17.0; SPSS, Chicago, IL, USA)

\section{Follow up}

Follow up visits were scheduled at 3, 6, 12, 18 months, to evaluate clinical and radiographic success of treatment. The teeth were evaluated by a qualified examiner who is blinded to the treatments.

\section{Clinical evaluation was done for}

1. History of pain.

2. Swelling.

3. Fistula.

4. Sensitivity to percussion.

5. Tooth movement

\section{Radiographic evaluation was done for}

1. Widened lamina dura

2. Periapical/furcal radiolucency

3. Internal/external root resorption

\section{The statistical methods}

Data were statistically described in term of mean \pm standard deviation $( \pm \mathrm{SD})$, median and range when appropriate. Data were explored for 
normality using Kolmogorov-Smirnov and ShapiroWilk tests, lab procedures data showed parametric (normal) distribution.

For parametric data, Independent sample t-test was used to compare between two groups in nonrelated samples. For non-parametric data, Mann Whitney test was used to compare between two groups in non-related samples. The significance level was set at $\mathrm{P} \leq 0.05$. Statistical analysis was performed with IBM ${ }^{\circledR}$ SPSS ${ }^{\circledR}$ Statistics Version 20 for Windows.

\section{RESULTS}

IL-1 $\alpha$, IL-6, and IL-8 were measured in all of the collected pulp samples $(\mathrm{n}=40)$ using ELISA. The results for determination of treatment outcomes were based on 38 teeth that were followed up clinically and radiographically for 18 months. Two patients were not maintained during the follow-up and these two cases considered failed cases.

\section{I) Lab results (cytokine level):}

\section{a) ILI $\alpha$ :}

There was a statistically significant difference of IL-1 $\alpha$ expression between (Group A) and (Group B) where $(p=0.014)$. The highest mean value was found in (Group B), while the lowest mean value was found in (Group A) as shown in table (1)

\section{b) IL6:}

There was a statistically significant difference between (Group A) and (Group B) where $(p=0.011)$. The highest mean value was found in (Group B), while the lowest mean value was found in (Group A) as shown in table (1)

\section{c) IL8:}

There was a statistically significant difference between (Group A) and (Group B) where ( $p=0.027)$. The highest mean value was found in (Group B), while the lowest mean value was found in (Group A) as shown in table (1)

TABLE (1): Comparison between cytokines levels in groups "A" and "B"

\begin{tabular}{|c|c|c|c|c|c|}
\hline \multirow{2}{*}{ Cytokines level } & \multicolumn{2}{|c|}{ Group A } & \multicolumn{2}{c|}{ Group B } & \multirow{2}{*}{ p-value } \\
\cline { 2 - 5 } & Mean & SD & Mean & SD & \\
\hline IL1 $\alpha$ & 3.12 & 0.66 & 3.82 & 0.99 & $0.014^{*}$ \\
\hline
\end{tabular}

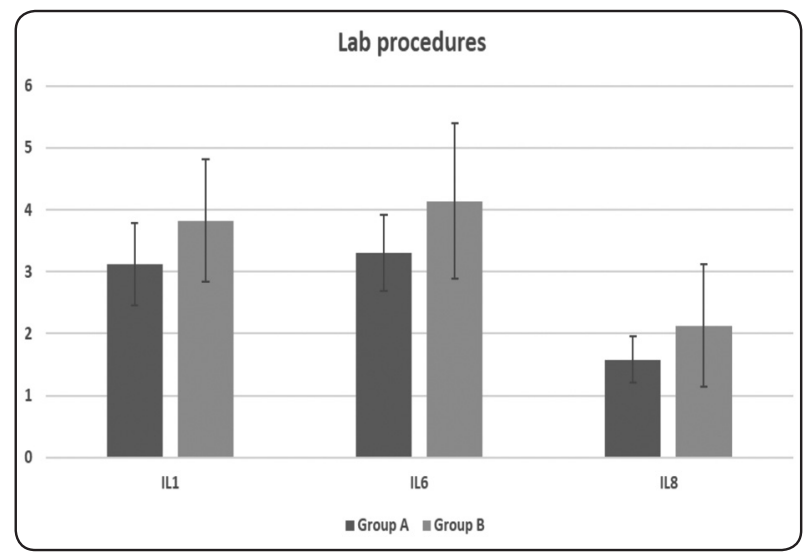

Fig. (1): Bar chart representing Cytokine levels for different groups. Notice the higher levels of IL-1 $\alpha$, IL- 6 \& IL-8 in group B.

\begin{tabular}{|c|c|c|c|c|c|}
\hline IL6 & 3.30 & 0.62 & 4.14 & 1.26 & $0.011^{*}$ \\
\hline IL8 & 1.58 & 0.37 & 2.13 & 0.99 & $0.027^{*}$ \\
\hline
\end{tabular}

*; significant $(p<0.05)$

\section{II) Clinical results}

Clinical evaluation was done for History of pain, Swelling, Fistula, sensitivity to percussion and tooth movement.

\section{A) Comparison within groups}

\section{a) Group A}

No statistically significant difference between $(3 \mathrm{~m}),(6 \mathrm{~m}),(12 \mathrm{~m})$ and $(18 \mathrm{~m})$ where $(p=0.392)$. One case in $(3 \mathrm{~m})$ time period showed clinical failure while all patients in all other time periods showed normal clinical parameters. 


\section{b) Group B}

No statistically significant difference between $(3 \mathrm{~m}),(6 \mathrm{~m}),(12 \mathrm{~m})$ and $(18 \mathrm{~m})$ where $(p=0.392)$. One case in $(6 \mathrm{~m})$ time period showed clinical failure while all patients in all other time periods showed normal clinical parameters.

\section{B) Comparison between groups}

\section{a) $3 m$}

No statistically significant difference between (Group A) and (Group B) where $(p=0.317)$. One case $1(5 \%)$ showed clinical failure in group A. While all patients in Group B showed normal clinical parameters.

\section{b) $6 m$}

No statistically significant difference between (Group A) and (Group B) where $(p=0.317)$. All patients in Group A showed normal clinical parameters. While one case $1(5 \%)$ showed clinical failure in group B.

\section{c) $12 \mathrm{~m}$ and $18 \mathrm{~m}$}

No statistically significant difference between (Group A) and (Group B) where $(p=1)$. All patients in all groups showed normal clinical parameters

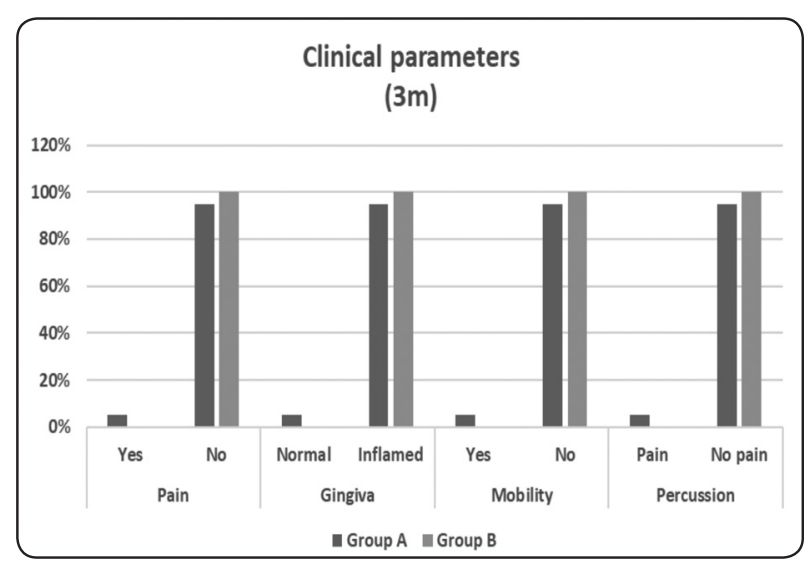

Fig. (2): Bar chart representing clinical parameters for different groups over the $3 \mathrm{~m}$ follow up period.

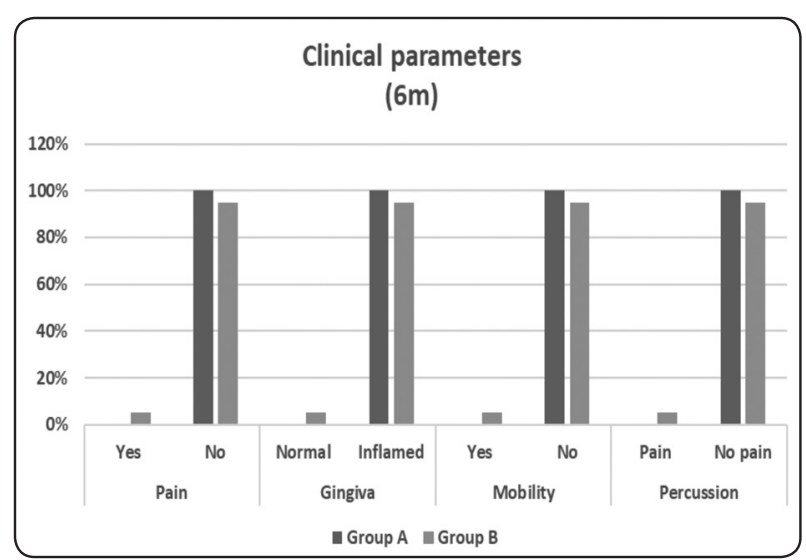

Fig. (3): Bar chart representing clinical parameters for different groups over the $6 \mathrm{~m}$ follow up period.

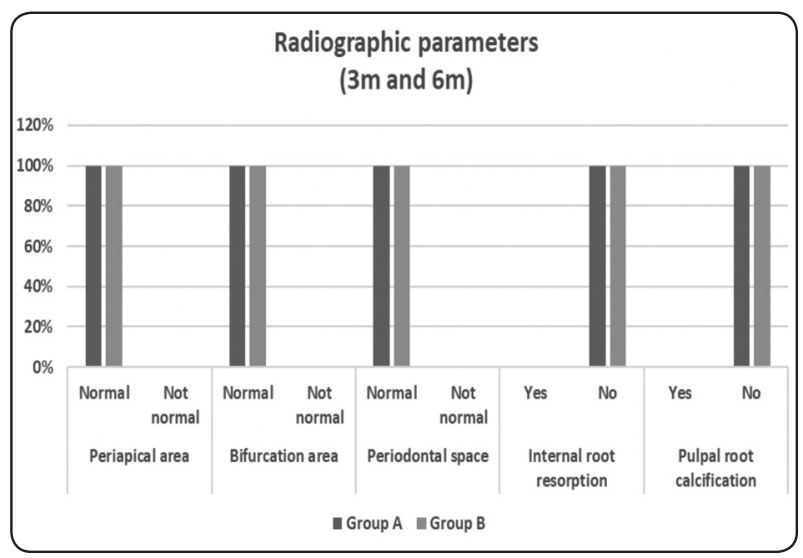

Fig. (4): Bar chart representing radiographic parameters for different groups at $3 \& 6$ months follow up.

\section{III) Radiographic results}

Radiographic evaluation was done for Widened lamina dura, Periapical/furcal radiolucency Internal/ external root resorption. The interexaminer kappa value was calculated and revealed 0.9

\section{A) Comparison within groups}

\section{a) Group A}

No statistically significant difference between $(3 \mathrm{~m}),(6 \mathrm{~m}),(12 \mathrm{~m})$ and $(18 \mathrm{~m})$ where $(p=1)$. All patients in all time periods showed normal radiographic parameters. 


\section{b) Group B}

No statistically significant difference between $(3 \mathrm{~m}),(6 \mathrm{~m}),(12 \mathrm{~m})$ and $(18 \mathrm{~m})$ where $(p=1)$. All patients in all time periods showed normal radiographic parameters.

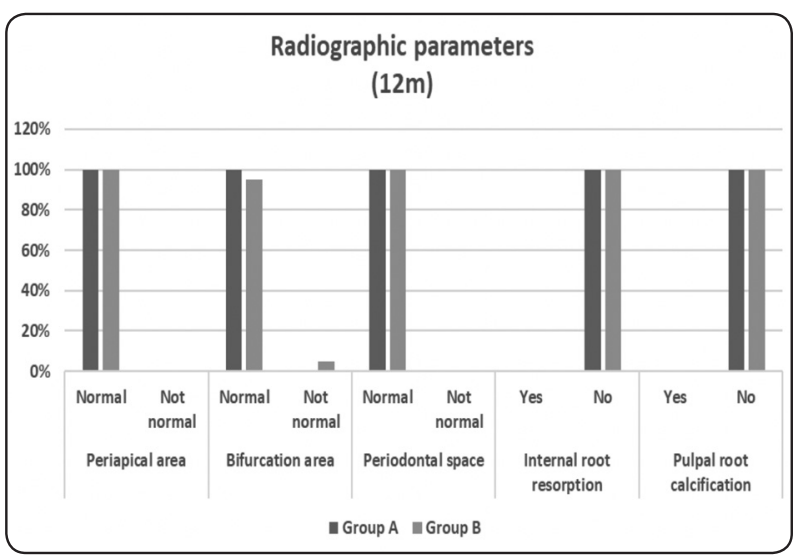

Fig. (5): Bar chart representing radiographic parameters for different groups at 12 months follow up.

\section{B) Comparison between groups}

No statistically significant difference between (Group A) and (Group B) over the follow up period 3 and 6 months where $(p=1)$. All patients in all groups showed normal radiographic parameters.

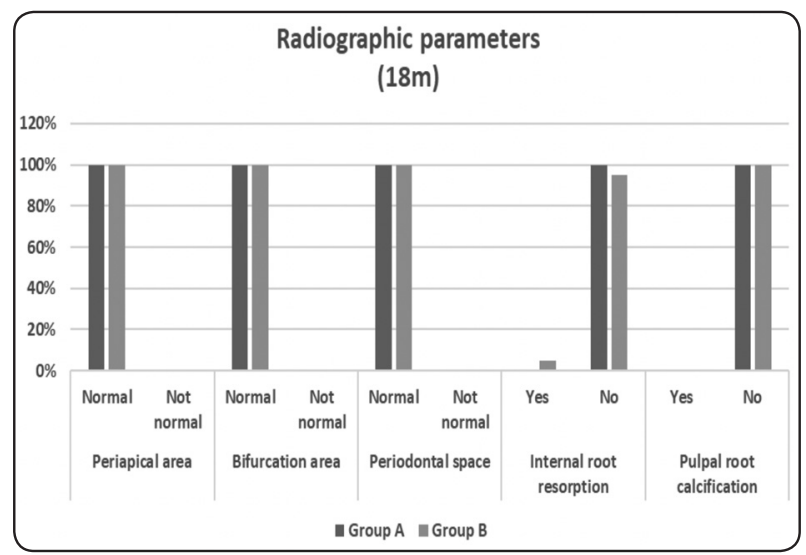

Fig. (6): Bar chart representing radiographic parameters for different groups at 18 months follow up.

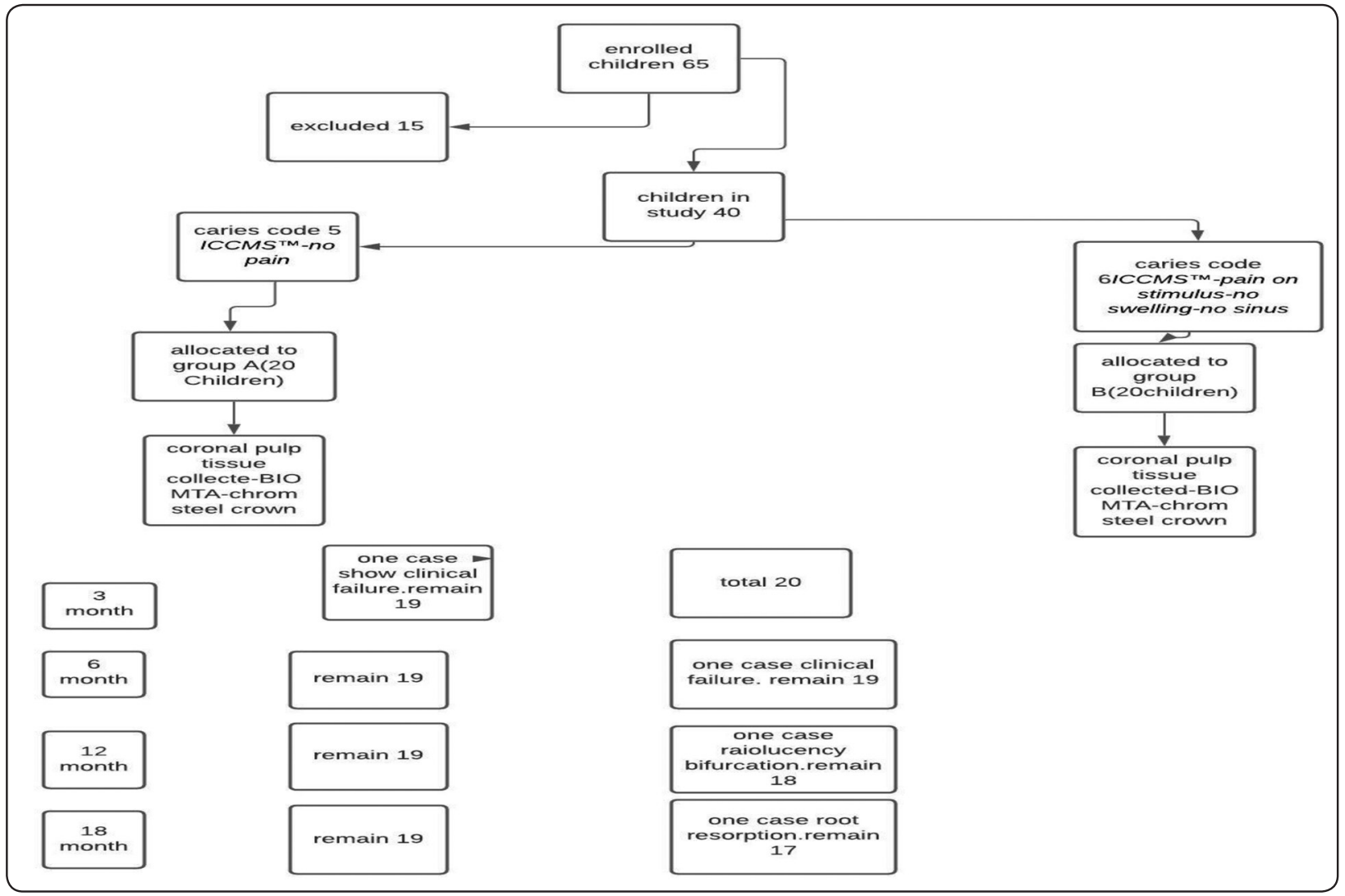

Fig. (7) patient flow chart in the study with 18 month follow up 


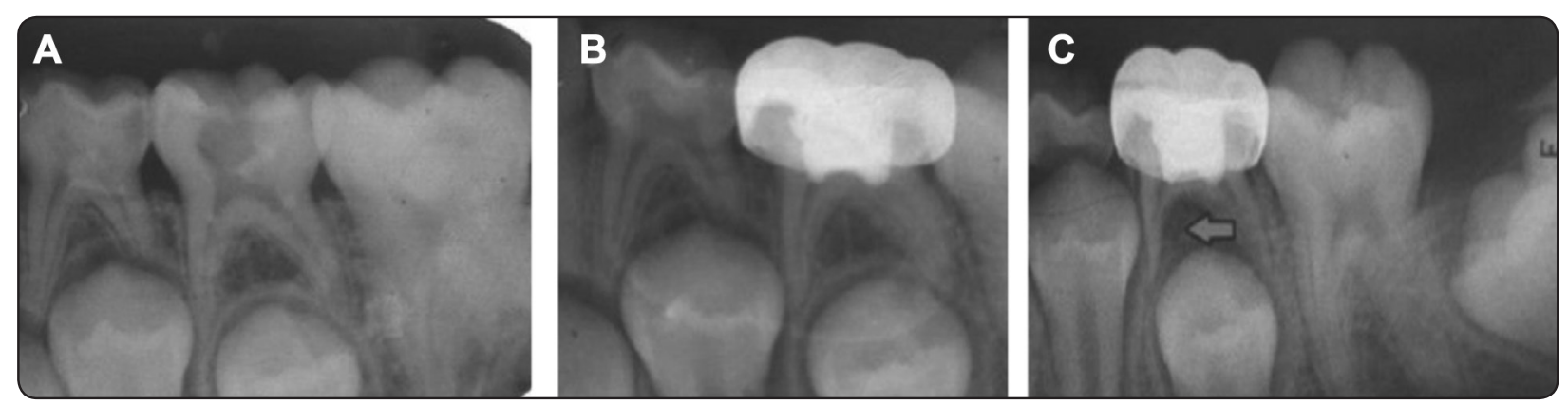

Fig. (8): A: preoperative photo of carious lower second primary molar stage 6 according to ICCM (group B). B: post postoperative after $3 \mathrm{~m}$. C: post-operative $12 \mathrm{~m}$, notice the radiolucency at the bifurcation area.

\section{c) $12 \mathrm{~m}$}

No statistically significant difference between (Group A) and (Group B) where $(p=0.317)$. All patients in Group A showed normal radiographic parameters. While one case $1(5 \%)$ showed radiolucency in bifurcation area in group B.

\section{d) $18 m$}

No statistically significant difference between (Group A) and (Group B) where $(p=0.317)$. All patients in Group A showed normal radiographic parameters. While one case $(5 \%)$ showed root resorption in Group B.

\section{DISCUSSION}

According to the AAPD "The Reference Manual of Pediatric Dentistry 2020”, controlling hemorrhage within the radicular pulp is of major important indicator of inflammatory status of pulp tissue. They reported that if the hemorrhage isn't controlled within the radicular pulp with a damp cotton pellet applied for several minutes this could be a sign of pulpectomy treatment ${ }^{[10]}$, they encouraged that clinicians shouldn't only depend upon sort of pain and level of caries but the inflammatory status of the pulp should be highly considered.

This study aimed to evaluate the biological condition of pulp as a factor affecting the success of pulpotomy treatment for primary teeth. In addition, the outcome of pulpotomy treatment was examined according to the degree of the caries extension to the pulp. It was reported that Pulpal inflammation increases in parallel with progression of carious lesions ${ }^{[35]}$. In order to decide the type of treatment for a deep carious lesion in a primary tooth, the dentist should determine the degree of pulpal inflammation. Most of the time, dentists rely on subjective signs that might give inaccurate indication about the reversibility of the pulpal condition. Hence an objective analysis of cytokine levels may quite possible provide such an accurate reflection of pulpal status ${ }^{[36]}$.

In the present study, comparison of the cytokine levels in group (A) \& group (B), we found that the levels of IL- $1 \alpha$, IL- 6 and IL- 8 were significant higher in group (B) than in (A), thus supporting previous researches that have shown these cytokines could be associated with pathogenesis of pulpal inflammation ${ }^{[37]}$.

Moreover, we found that the IL-6 showed the most significant value of expression in comparison to IL- $1 \alpha$ and IL-8 (p-value: $0.011,0.014 \& 0.027$ respectively) which denote the prominent role of IL-6 during the inflammatory process in the pulp tissue of primary molars. Which support the results presented by Zehnder et al., they detected a positive correlation between IL-6 and IL-8 in inflamed pulp ${ }^{[38]}$. 
An interesting observation reported by Wisithphrom and Windsor, 2011, they found that the rise in amount of IL6 brings about collagen degradation which in turn is associated with pulpal destruction. Also they revealed that IL-6 causes modulation of adhesion molecules and effects angiogenesis, a process which induces vascular permeability and generates inflammatory edema ${ }^{[27]}$. Previous studies revealed that, rise in IL- 1 , IL- 8 propagate acute inflammation ${ }^{[39]}$; IL-6 is also correlated with edema and pulpal degeneration ${ }^{[40]}$

On the other hand; when used samples from permanent teeth, Elsahly et al .2013 found no statistically significant differences between the levels of IL-6 of teeth requiring direct pulp capping and those with irreversible pulpitis. The authors explained that this might be due to the variation in the intensity of pulpal inflammation between pulp chamber and root canals of those teeth. On the other hand; for samples of permanent teeth, Elsahly et al. 2013 found no statistically significant differences between the levels of IL-6 of teeth requiring direct pulp capping and those with irreversible pulpitis. The authors explained that this might be due to the variation in the intensity of pulpal inflammation between pulp chamber and root canals of those teeth. ${ }^{[32]}$.

In the present study the levels of IL-6 and IL-1 $\alpha$ were more highly significantly and might be a good indicators of degree of pulp inflammation in deep carious molar with pain upon stimulus than in primary molar with no pain. In addition we found that IL-8 was significantly higher in group B than group a demonstrating that, these cytokines are associated with pulpal advanced inflammation.

The previous observation are in agreement with study done by Ozdemir et al. 2015, they revealed that IL-6 and IL-8 levels were significantly upregulate in cariously exposed pulp of primary molar when compared to other group of the mechanically exposed pulp of primary molars. They suggested that IL-6 and IL-8 levels might have a role indica- tion in the accuracy of prognosis in vital pulp therapy ${ }^{[41]}$. Moreover, they found no significant increase of the IL- $1 \alpha$ level in carious exposed teeth relative to mechanically exposed teeth. The same observation was revealed by Matthias Zehnder et al. they found no significant change in IL-1 $\alpha$ levels between healthy and non-symptomatic carious teeth ${ }^{[38]}$.

In the present study, the expression of IL-6, was found to be significantly higher in teeth with deep caries (group B) when compared to teeth with no pain and less deep caries lesions (group A). And this is due to upregulation in both IL-6 and IL- 8 in the advanced stage of inflammation which is associated with edema, As explained by Ferreira et al, 2009, chronic inflammation occurs in the coronal pulp of primary teeth with deep caries, as well as bacterial invasion may increase the inflammatory response ${ }^{[2,42]}$.

In the present study, the higher expression of IL-1 in group B in deep carious lesions could be explained as the precursor of IL-1 is released when tissue damage happens. So, its presence in dental pulp might indicate irreversible and more tissue edema and degeneration ${ }^{[38]}$.

According to the findings of the current study, there were significant differences in the levels of IL- $1 \alpha$, IL- 6 and IL- 8 cytokines between group A and $\mathrm{B}$. the difference of interleukins expression in the present study could be affected by the depth of caries between the two groups. As well as it could be postulated that these cytokine levels might reflect the degree of inflammation and tissue degeneration in the pulp tissue of primary molars.

The result showed that there is no significant difference during the clinical follow up in both groups during the 18 months. In group $\mathrm{B}$, one case showed radiolucency in bifurcation area at 12 months and the another case showed external root resorption after at 18 months follow up, these two cases showed the highest level of IL- 8 which indicate they were highly inflamed. A third case in group B was not maintained during the follow up 
period at 6 month and was considered one of the failed cases. In group A, one case was failed because it was not maintained at the three month follow up period till the end of 18 months.

For pathologically exposed teeth, vital pulpotomy is usually performed based on an assumption that inflammation is restricted to coronal pulp ${ }^{[11,15]}$. Nevertheless, studies showed that this might not always be the case. For example, Kassa et al 2009 claimed that in primary molars with proximal caries lesions extending deeper than $50 \%$ of dentin thickness, inflammation in coronal pulp takes longer time to cause pulp exposure and that carious exposure wasn't the sole explanation for coronal pulpal inflammation ${ }^{[16]}$.

Interestingly, within the present study, although the significant difference within the cytokine level expression between group A and B with more advanced inflammatory status in group B, we found a high success rate of most of the cases during the follow up period in both groups apart from one case failed in group A (didn't complete the follow up) $(5 \%)$ and three cases failed in group B (radiolucency at furcation area \& root resorption) (15\%). We could say that the careful clinical examination and history taking from the cases as well as the proper isolation of primary teeth with rubber dam during treatment procedure and using the MTA material as pulpotomy agent and restoration of the treated teeth with full coverage chrome steel crowns might have impact on the success rate of the cases with good prognostic anticipation although the various inflammatory status of the pulp tissue in both groups. This finding of the present study supports the recommendation provided by AAPD 'The Reference Manual of Pediatric Dentistry 2020" to increase the success rate of vital pulp therapy in primary teeth ${ }^{[10]}$.

Another interesting observation reported by Asgary and Ehsani.2009, revealed that in permanent molars with extensive pulpal inflammation or even periapical pathosis, pulpotomy yielded higher clinical and radiographic success rates than root canal treatment after two years follow up ${ }^{[43]}$. Moreover, Waterhouse et al.2011, reported that there was no significant difference between inflamed and non-inflamed pulps regarding time needed for hemostasis ${ }^{[27]}$. These studies adopt different concepts on the effect of pulpal inflammation and treatment outcomes. They suggested that the factors controlling the degree of pulpal inflammatory status and hence a successful pulpotomy might be broader than the current conventional parameters ${ }^{[43,27]}$.

The limitations of this study include the relatively strict eligibility criteria which could affect the generality of the results. So further studies could be needed to research the effect of inflammatory status of pulp tissue on the prognosis of pulp therapy in primary teeth putting in consideration different variables.

\section{CONCLUSION}

IL-1 $\alpha$, IL-6 and IL-8 cytokine expression in primary pulp molars increase with caries progression. So these cytokines might reflect the degree of inflammation and tissue degeneration of pulp at the canal orifices in carious primary teeth. IL-1 $\alpha$ IL-6 and IL- 8 might be good indicators for the severity of pulp inflammation. Whenever possible in the clinical practice, measuring levels of IL- $1 \alpha$ IL- 6 and IL- 8 by ELIZA could be accurate tool to detect degree of pulp inflammation and hence the prognostic outcome of vital pulp therapy.

\section{ACKNOWLEDGEMENTS}

The authors acknowledge the medical team work that supported our work during the clinical procedures and sample collection at the outpatient clinic of MUST University. Cairo. Egypt.

\section{Funding}

Self-funded 


\section{Conflict of interest}

The authors declare that they have no conflict of interest.

\section{REFERENCES}

1. Cavalcanti BN, Rode Sde M, França CM, Marques MM. Pulp capping materials exert an effect on the secretion of IL-1 $\beta$ and IL-8 by migrating human neutrophils. Braz Oral Res. 2011 Jan-Feb;25(1):13-8. doi: 10.1590/s180683242011000100003. PMID: 21359446.

2. Ferreira DC, Brito DG, Cavalcanti BN. Cytokine production from human primary teeth pulp fibroblasts stimulated by different pulpotomy agents. J Dent Child (Chic). 2009 Sep-Dec;76(3):194-8. PMID: 19941760.

3. Elsalhy M, Azizieh F, Raghupathy R. Cytokines as diagnostic markers of pulpal inflammation. Int Endod J. 2013 Jun;46(6):573-80. doi: 10.1111/iej.12030. Epub 2012 Dec 13. PMID: 23240887.

4. Waterhouse PJ, Nunn JH, Whitworth JM. Prostaglandin E2 and treatment outcome in pulp therapy of primary molars with carious exposures. Int $\mathrm{J}$ Paediatr Dent. 2002 Mar;12(2):116-23. doi: 10.1046/j.1365263x.2002.00321.x. PMID: 11966889.

5. Holan G, Eidelman E, Fuks AB. Long-term evaluation of pulpotomy in primary molars using mineral trioxide aggregate or formocresol. Pediatr Dent. 2005 MarApr;27(2):129-36. PMID: 15926290.

6. Ranly DM, Garcia-Godoy F. Current and potential pulp therapies for primary and young permanent teeth. J Dent. 2000 Mar;28(3):153-61. doi: 10.1016/s03005712(99)00065-2. PMID: 10709337.

7. Fuks AB. Current concepts in vital primary pulp therapy. Eur J Paediatr Dent. 2002 Sep;3(3):115-20. PMID: 12870999.

8. Ibricevic H, al-Jame Q. Ferric sulfate as pulpotomy agent in primary teeth: twenty month clinical follow-up. J Clin Pediatr Dent. 2000 Summer;24(4):269-72. doi: 10.17796/ jcpd.24.4.d7u6405nw1132705. PMID: 11314410..

9. Raslan N, Wetzel WE. Exposed human pulp caused by trauma and/or caries in primary dentition: a histological evaluation. Dent Traumatol. 2006 Jun;22(3):145-53. doi: 10.1111/j.1600-9657.2006.00410.x. PMID: 16643290.
10. American Academy of Pediatric Dentistry. Pulp therapy for primary and immature permanent teeth. The Reference Manual of Pediatric Dentistry. Chicago, Ill.: American Academy of Pediatric Dentistry; 2020:384-92.

11. [cDonald RE, Avery DR, Dean JA. Treatment of deep caries, vital pulp exposure and pulpless teeth. In: Mc Donald RE, Avery DR, eds. Dentistry for the Child and Adolescent. 8th ed. St. Louis, Mo., USA: Mosby; 2004: 388-412.

12. Sonmez D, Duruturk L. Success rate of calcium hydroxide pulpotomy in primary molars restored with amalgam and stainless steel crowns. Br Dent J. 2010 May 8;208(9):E18; discussion 408-9. doi: 10.1038/sj.bdj.2010.446. PMID: 20448584

13. Rider P, Carmi Y, Voronov E, Apte RN. Interleukin-1 $\alpha$. Semin Immunol. 2013 Dec 15;25(6):430-8. doi: 10.1016/j. smim.2013.10.005. Epub 2013 Nov 1. PMID: 24183701.

14. Horst OV, Horst JA, Samudrala R, Dale BA. Caries induced cytokine network in the odontoblast layer of human teeth. BMC Immunol. 2011 Jan 24;12:9. doi: 10.1186/14712172-12-9. PMID: 21261944; PMCID: PMC3036664..

15. Rodd HD, Waterhouse PJ, Fuks AB, Fayle SA, Moffat MA; British Society of Paediatric Dentistry. Pulp therapy for primary molars. Int J Paediatr Dent. 2006 Sep;16 Suppl 1:15-23. doi: 10.1111/j.1365-263X.2006.00774.x. PMID: 16939452

16. Kassa D, Day P, High A, Duggal M. Histological comparison of pulpal inflammation in primary teeth with occlusal or proximal caries. Int J Paediatr Dent. 2009 Jan;19(1):26-33. doi: 10.1111/j.1365-263X.2008.00962.x. PMID: 19120507..

17. Hunter CA, Jones SA. IL-6 as a keystone cytokine in health and disease. Nat Immunol. 2015 May;16(5):448-57. doi: 10.1038/ni.3153. Erratum in: Nat Immunol. 2017 Oct 18;18(11):1271. PMID: 25898198.

18. Wisithphrom K, Windsor LJ. The effects of tumor necrosis factor-, interleukin-1, interleukin-6 and transforming growth factor-1 on pulp fibroblast mediated collagen degradation. J Endod 2006;32:853-61

19. Hahn CL, Liewehr FR. Innate immune responses of the dental pulp to caries. J Endod 2007;33:643-51

20. Nibali L, Fedele S, D'Aiuto F, Donos N. Interleukin-6 in oral diseases: a review. Oral Dis. 2012 Apr;18(3):236-43. doi: 10.1111/j.1601-0825.2011.01867.x. Epub 2011 Nov 4. PMID: 22050374. 
21. Abbas A.K., Lichtman A.H., Pillai S. sixth ed. Saunders; Philadelphia: 2007. Cellular and Molecular Immunology.

22. Hahn CL, Liewehr FR. Innate immune responses of the dental pulp to caries. J Endod. 2007 Jun;33(6):643-51. doi: 10.1016/j.joen.2007.01.001. Epub 2007 Mar 6. PMID: 17509400 .

23. de Sá AR, Pimenta FJ, Dutra WO, Gomez RS. Immunolocalization of interleukin 4 , interleukin 6 , and lymphotoxin alpha in dental granulomas. Oral Surg Oral Med Oral Pathol Oral Radiol Endod. 2003 Sep;96(3):356-60. doi: 10.1016/s1079-2104(03)00067-2. PMID: 12973294.

24. Prso IB, Kocjan W, Simić H, Brumini G, Pezelj-Ribarić S, Borcić J, Ferreri S, Karlović IM. Tumor necrosis factor-alpha and interleukin 6 in human periapical lesions. Mediators Inflamm. 2007;2007:38210. doi: 10.1155/2007/38210. Epub 2006 Dec 27. PMID: 17497030; PMCID: PMC1804300.

25. Zhao X, Lin CW, Wang J, Oh DH. Advances in rapid detection methods for foodborne pathogens. J Microbiol Biotechnol. 2014 Mar 28;24(3):297-312. doi: 10.4014/ jmb.1310.10013. PMID: 24375418.

26. Wisithphrom K, Windsor LJ. The effects of tumor necrosis factor-alpha, interleukin-1beta, interleukin-6, and transforming growth factor-betal on pulp fibroblast mediated collagen degradation. J Endod. 2006 Sep;32(9):853-61. doi: 10.1016/j.joen.2006.03.017. Epub 2006 Jul 3. PMID: $16934628 .$.

27. Waterhouse P, Whitworth J, Camp J, Fuks A. Pediatric endodontics: endodontic treatment for the primary and young permanent dentition. In: Hargreaves KM, Cohen S, eds. Cohen's Pathways of the Pulp. St. Louis, Mo., USA: Mosby;2011:808-57.

28. Aeinehchi M, Dadvand S, Fayazi S, Bayat-Movahed S. Randomized controlled trial of mineral trioxide aggregate and formocresol for pulpotomy in primary molar teeth. Int Endod J. 2007 Apr;40(4):261-7. doi: 10.1111/j.13652591.2007.01209.x. Epub 2007 Feb 19. PMID: 17309744.

29. Moretti AB, Sakai VT, Oliveira TM, Fornetti AP, Santos CF, Machado MA, Abdo RC. The effectiveness of mineral trioxide aggregate, calcium hydroxide and formocresol for pulpotomies in primary teeth. Int Endod J. 2008 Jul;41(7):547-55. doi: 10.1111/j.1365-2591.2008.01377.x. Epub 2008 May 12. PMID: 18479381.

30. Ismail AI, Pitts NB, Tellez M, et al. The International Caries Classification and Management System (ICCMS ${ }^{\mathrm{TM}}$ )
An Example of a Caries Management Pathway. BMC Oral Health. 2015;15 Suppl 1(Suppl 1):S9. doi:10.1186/14726831-15-S1-S9

31. Mutluay M, Arıkan V, Sarı S, Kısa Ü. Does Achievement of Hemostasis After Pulp Exposure Provide an Accurate Assessment of Pulp Inflammation? Pediatr Dent. 2018 Jan 1;40(1):37-42. PMID: 29482681.

32. Elsalhy M, Azizieh F, Raghupathy R. Cytokines as diagnostic markers of pulpal inflammation. Int Endod J. 2013 Jun;46(6):573-80. doi: 10.1111/iej.12030. Epub 2012 Dec 13. PMID: 23240887.

33. Coil J, Tam E, Waterfield JD. Proinflammatory cytokine profiles in pulp fibroblasts stimulated with lipopolysaccharide and methyl mercaptan. J Endod. 2004 Feb;30(2):88-91. doi: 10.1097/00004770-20040200000006. PMID: 14977303 ..

34. Pezelj-Ribaric S, Anic I, Brekalo I, Miletic I, Hasan M, Simunovic-Soskic M. Detection of tumor necrosis factor alpha in normal and inflamed human dental pulps. Arch Med Res. 2002 Sep-Oct;33(5):482-4. doi: 10.1016/s01884409(02)00396-x. PMID: 12459320.

35. Ekstrand KR, Luna LE, Promisiero L, et al. The reliability and accuracy of two methods for proximal caries detection and depth on directly visible proximal surfaces: an in vitro study. Caries Res. 2011;45(2):93-99. doi: $10.1159 / 000324439$.

36. Rechenberg DK, Galicia JC, Peters OA. Biological Markers for Pulpal Inflammation: A Systematic Review. PLoS One. 2016 Nov 29;11(11):e0167289. doi: 10.1371/ journal.pone.0167289. PMID: 27898727; PMCID: PMC5127562.

37. Bazzoni F, Tamassia N, Rossato M, Cassatella MA. Understanding the molecular mechanisms of the multifaceted IL-10-mediated anti-inflammatory response: lessons from neutrophils. Eur J Immunol. 2010;40(9):23602368. doi:10.1002/eji.200940294.

38. Zehnder M, Delaleu N, Du Y, Bickel M. Cytokine gene expression--part of host defence in pulpitis. Cytokine. 2003 May;22(3-4):84-8. doi: 10.1016/s1043-4666(03)00116-9. PMID: 12849707..

39. Silva AC, Faria MR, Fontes A, Campos MS, Cavalcanti BN. Interleukin- 1 beta and interleukin- 8 in healthy and inflamed dental pulps. J Appl Oral Sci. 2009 Sep-Oct;17(5):527-32. doi: 10.1590/s1678-77572009000500031. PMID: 19936537; PMCID: PMC4327685. 
40. Fujii M, Kawashima N, Tazawa K, Hashimoto K, Nara K, Noda S, Kuramoto M, Orikasa S, Nagai S, Okiji T. HIF1 $\alpha$ inhibits LPS-mediated induction of IL-6 synthesis via SOCS3-dependent CEBP $\beta$ suppression in human dental pulp cells. Biochem Biophys Res Commun. $2020 \mathrm{Feb}$ 5;522(2):308-314. doi: 10.1016/j.bbrc.2019.11.032. Epub 2019 Nov 22. PMID: 31767145.

41. Ozdemir Y, Kutukculer N, Topaloglu-Ak A, Kose T, Eronat C. Comparative evaluation of pro-inflammatory cytokine levels in pulpotomized primary molars. J Oral Sci. 2015
Jun;57(2):145-50. doi: 10.2334/josnusd.57.145. PMID: 26062864 ..

42. Coll JA, Seale NS, Vargas K, Marghalani AA, Al Shamali S, Graham L. Primary Tooth Vital Pulp Therapy: A Systematic Review and Meta-analysis. Pediatr Dent. 2017 Jan 15;39(1):16-123. PMID: 28292337.

43. Asgary S, Ehsani S. Permanent molar pulpotomy with a new endodontic cement: A case series. J Conserv Dent. 2009 Jan;12(1):31-6. doi: 10.4103/0972-0707.53340. PMID: 20379438; PMCID: PMC2848811. 